\title{
Pemaknaan Pakaian Khas Masyarakat Sedulur Sikep Sebagai Identitas Sosial
}

\author{
Agustin Ellaelatun Nurul Hafidhoh ${ }^{1}$ \\ Fakultas Psikologi dan Kesehatan, Program Psikologi, UIN Walisongo Semarang \\ Agustinellaelatun@gmail.com \\ Rifqi Ishlah Fadhli ${ }^{2}$ \\ Fakultas Psikologi dan Kesehatan, Program Psikologi, UIN Walisongo Semarang \\ Ishlahrifqi1723@gmail.com \\ Nikmah Rochmawati ${ }^{3}$ \\ Universitas Islam Negeri Walisongo Semarang \\ rahma_mewangi@walisongo.ac.id
}

\begin{abstract}
The purpose of this research is to find out why the Sedulur Sikep people still maintain their culture from the past to the present and whether there is a philosophy of their own related to the typical clothes they wear. The methods used in this research are observation and interviews. The results of this study are the aim of the Sedulur Sikep community to maintain their distinctive dress code, namely to respect their fellow Sedulur Sikep. In addition, it is proof that Sedulur Sikep still holds noble values that have been passed down from its predecessors and are not eroded by time. The distinctive dress code of Sedulur Sikep is a distinct characteristic that distinguishes it from other groups. And also reflects how they relate to fellow God's creatures and they are able to place themselves in their respective roles and practice the teachings that have been passed down from their predecessors
\end{abstract}

Keywords: Teachings, Sedulur Sikep, culture, typical clothes, Ajining Raga Ana Ing Clothing

\begin{abstract}
Abstrak
Tujuan penelitian ini yaitu untuk mengetahui mengapa masyarakat Sedulur Sikep masih mempertahankan kebudayaan mereka dari dulu hingga sekarang dan apakah terdapat makna terkait pakaian khas yang mereka gunakan tersebut. Metode yang digunakan dalam penelitian ini yaitu observasi dan wawancara. Hasil dari penelitian ini adalah tujuan dari masyarakat Sedulur Sikep tetap mempertahankan cara berpakaian khas mereka yaitu untuk menghargai sesama Sedulur Sikep. Selain itu menjadi bukti bahwa Sedulur Sikep masih memegang nilai-nilai luhur yang telah diturunkan dari para pendahulunya dan tidak tergerus oleh zaman. Cara berpakaian yang khas dari Sedulur Sikep merupakan karakteristik tersendiri yang membedakannya dengan kelompok lain. Dan juga mencerminkan bagaimana mereka berhubungan antar sesama makhluk ciptaan Tuhan serta mereka mampu
\end{abstract}


menempatkan diri mereka pada perannya masing-masing dan mengamalkan ajaran yang telah diwariskan dari pendahulunya.

Kata kunci: Ajining Raga Ana Ing Busana, Ajaran Sedulur Sikep, Kebudayaan, Pakaian khas

\section{PENDAHULUAN}

Indonesia merupakan negara dengan berbagai suku dan bangsa. Salah satunya suku Samin (Sedulur Sikep) yang terdapat di kabupaten Pati. Masyarakat Suku Samin (Sedulur Sikep) ini adalah sekelompok masyarakat yang mempercayai dan menganut ajaran dari pemimpin masyarakat Samin yaitu Samin Surosentiko (Purwasito, 2003). Budaya samin ini sebagai sikap dan kepercayaan masyarakat yang tidak memberi banyak peluang untuk masuk dan tumbuhnya budaya baru di masyarakat tersebut. Karena menurut ajaran saminisme, orang yang berada di kelompok masyarakat Samin harus rajin bekerja, memiliki sikap budi pekerti, mencintai alam semesta dan tidak boleh mencuri milik orang lain.

Meski begitu masyarakat Sedulur Sikep dapat menerima hadirnya budaya populer dan perkembangnya teknologi informasi.Tetapi masyarakat samin tetap menjaga kemurnian ajaran dari Sedulur Sikep. Menurut hasil penelitian dari Widyatwati (2017) mengatakan bahwa masyarakat Sedulur Sikep ini tetap menerima budaya populer dengan sikap dan ajaran Sedulur Sikep. Mereka tetap mempertahankan ajaran dan kebudayaan mereka sesuai dengan porsinya walaupun kebudayaan populer masuk ke ranah kehidupan masyarakat Sedulur Sikep. Misalnya masyarakat Sedulur Sikep mulai menggunakan hp dan listrik untuk kehidupan sehari-harinya.

Menurut Mbah Sriyono (juru kunci Omah Kendeng), Masyarakat Sedulur Sikep ini merupakan kelompok masyarakat yang konsisten dalam berperilaku. Mereka menjunjung tinggi nilai kejujuran, keadilan, tidak iri dengki dan bersikap serta bertindak apa adanya. Mereka tidak mau membuat orang lain merasa kesusahan akibat tindakannya. Hal ini telah sesuai dengan ajaran Samin Surosentiko yaitu tidak pernah mengagungkan pemimpinnya karena yang mereka agungkan adalah sikap kebudayaan mereka, yang dapat disimpulkan sebagai "akhlak" terpuji (Widiyanto,1983).

Dalam ajaran saminisme, Masyarakat Sedulur Sikep mempunyai prinsip yang sampai sekarang masih dipegang teguh oleh mereka. Budaya-budaya yang ada di masyakarat Sedulur Sikep diantaranya masyarakat Sedulur Sikep tidak diperbolehkan untuk menempuh pendidikan formal, tidak boleh berdagang, tidak boleh memakai peci, tidak boleh mempunyai istri dua, 
tidak boleh asal dalam berbicara dan bertindak. Selain itu masyarakat Sedulur Sikep juga mempunyai pakaian khas di mana untuk laki-laki menggunakan pakaian serba hitam dan menggunakan ikat kepala atau udeng. Sedangkan untuk perempuan menggunakan kebaya.

Kebudayaan-kebudayaan tersebut merupakan sebagai identitas sosial Sedulur Sikep yang membedakannya dengan kelompok masyarakat lain. Menurut Gunarsa (2003) identitas dapat diartikan sebagai suatu inti pribadi yang tetap ada walaupun mengalami perubahan bertahap dengan perkembangan umur dan perkembangan lingkungan. Gunarsa juga menambahkan bahwa identitas juga dapat diartikan sebagai cara hidup tertentu yang sudah dibentuk pada masa-masa sebelumnya dan menentukan peranan sosial manakah yang harus dijalankan.

Sedangkan Leary dan Tangney (2012) menyatakan identitas merupakan ciri-ciri dan karakteristik, hubungan sosial, peran, dan keanggotaan kelompok sosial yang menentukan siapa individu tersebut. Identitas dapat difokuskan pada masa lalu, masa sekarang, atau masa depan, di mana seseorang merasa wajib untuk mencoba untuk menjadi "siapa", atau ketakutan seseorang dapat menjadi "siapa". Maka dari itu dalam menentukan siapa mereka yaitu dengan membentuk suatu identitas sosial. Sedangkan menurut Jackson and Smith (1999) identitas sosial adalah tentang apa yang seorang individu miliki secara bersama-sama dengan lingkungan sosial di sekitarnya dan apa yang membedakan individu tersebut dengan lingkungan sekitarnya. Identitas sosial pada masyarakat Sedulur Sikep ini mencakup konsep diri, hubungan mereka dengan kelompok sosial lainnya, afiliasi etnis dan agama, pekerjaan, dan lain sebagainya. Termasuk bagaimana kelompok masyarakat Sedulur Sikep memaknai cara berpakaian mereka sebagai identitas sosialnya. Dan bagaimana kelompok lain memandang mereka melalui kebudayaannya.

Maka dari itu budaya masyarakat Sedulur Sikep ini merupakan sesuatu yang cukup menarik untuk diteliti. Salah satunya mengenai pakaian yang digunakan oleh masyarakat Sedulur Sikep ini. Mengapa mereka masih mempertahankan cara berpakaian mereka dari dulu hingga sekarang dan apakah ada filosofi tersendiri bagi masyarakat Sedulur Sikep mengenai pakaian khas tersebut. Karena diketahui masyarakat Sedulur Sikep ini masih menggunakan pakaian-pakaian khasnya meski hanya jika ada acara-acara tertentu yang mengharuskan mereka memakai pakaian khas mereka.

Menurut penelitian dari Utami, V. A., dan Irhandayaningsih, A. (2016) mengungkapkan salah satu kegiatan Sedulur Sikep yang masih melekat dan selalu menggunakan pakaian 
khasnya yaitu setiap setahun sekali masyarakat yang dilaksanakan berdasarkan akhir tahun kalender jawa. Selain itu juga dipakai ketika ada acara nikahan oleh masyarakat Sedulur Sikep lainnya. Pakaian khas yang digunakan oleh masyarakat Sedulur Sikep ini lebih cenderung pada semangat primordialisme kelompok. Karena masyarakat Sedulur Sikep ini menjunjung tinggi nilai-nilai yang diajarkan oleh orang tua mereka sejak dulu serta menghormati para leluhurleluhur Sedulur Sikep terdahulu.

Hal ini diketahui pada penelitian dari Munadi (2014) mengungkapkan ajaran hidup yang unik dari masyarakat Sedulur Sikep tersebut ditanamkan kepada generasi penerusnya oleh orang tuanya sejak lahir dengan bekal teladan baik untuk keluarga dan kehidupan sosialnya. Dan ajaran yang ditanamkan oleh Sedulur Sikep ini memang hanya diterapkan oleh masyarakat Sedulur Sikep. Hal ini dijadikan sebagai identitas sosialnya agar masyarakat umum dapat mengenali mereka sebagai masyarakat Sedulur Sikep.

Maka dari itu berdasarkan latar belakang di atas dalam artikel ini penulis ingin mengungkapkan mengenai pemaknaan berpakaian masyarakat Sedulur Sikep yang berada di Desa Sukolilo Kabupaten pati sebagai identitas sosial.

\section{METODE}

Metode penelitian yang digunakan dalam penelitian ini adalah dengan pendekatan kualitatif. Pendekatan kualitatif yaitu metode penelitian yang berusaha memahami dengan menggambarkan atau melukiskan fenomena yang diteliti secara sistematis, faktual, dan akurat mengenai fakta-fakta yang diamati (Creswell, 2014).

Dalam mengumpulkan data, peneliti menggunakan teknik observasi dan wawancara. Menurut Zainal Arifin dalam buku (Kristanto, 2018) observasi adalah suatu proses yang didahului dengan pengamatan kemudian pencatatan yang bersifat sistematis, logis, objektif, dan rasional terhadap berbagai macam fenomena dalam situasi yang sebenarnya, maupun situasi buatan. Sedangkan menurut A. Muri Yusuf (2014), wawancara adalah suatu kejadian atau suatu proses interaksi antara pewawancara (interviewer) dan narasumber yang akan diwawancarai (interviewee) melalui komunikasi langsung. Pada penelitian kali ini peneliti dalam mengumpulkan data yaitu dengan melakukan wawancara dengan ketiga narasumber yaitu Mbah Sriyono (80) dan Ibu Gunarti (49) selaku tokoh masyarakat Sedulur Sikep dan Ibu Nur (40) selaku masyarakat sekitar yang berada di lingkungan Sedulur Sikep. 
Kemudian data yang sudah diperoleh peneliti akan dianalisis dengan menggunakan metode deskripsi. Tujuan dari metode deskriptif ini adalah untuk membuat penjelasan akurat mengenai fakta-fakta, sifat-sifat serta hubungan antar fenomena yang terjadi (Nazir, 2005).

Dengan demikian diharapkan menggunakan metode penelitian ini mampu mendapat data yang sesuai dengan tujuan penelitian. Mampu menjawab permasalahan yang ditentukan oleh peneliti.

\section{HASIL DAN PEMBAHASAN}

Berdasarkan hasil observasi dan wawancara peneliti dengan ketiga narasumber yang merupakan kelompok masyarakat Sedulur Sikep di Sukolilo mengungkapkan bahwa Sedulur Sikep yang berada disana tetap mempertahankan dan melestarikan kebudayaan yang sudah ada sejak dulu yaitu menganut ajaran saminisme yang dibawa oleh Samin Surosentiko. Mereka tetap menjaga kebudayaan tersebut karena mereka merasa hal tersebut merupakan sebuah amanah dari para orang tua mereka terdahulu.

Kelompok masyarakat Sedulur Sikep dari dahulu sampai sekarang masih memegang teguh prinsip yang mereka terapkan dalam kehidupan sehari-hari. Menurut penuturan dari salah satu sesepuh Sedulur Sikep yaitu Mbah Sriyono (80) mengungkapkan, Sedulur Sikep selalu menerapkan sikap budi pekerti, berperilaku jujur dan adil, tidak mudah merasa dengki, iri hati, mencuri, berbohong, saling membantu dan juga ramah. Sedulur Sikep sendiri jika menemukan sebuah barang di dekat rumah mereka maupun di jalan, mereka tidak akan mengambil barang tersebut walaupun itu sudah sampai berhari-hari di sana. Hal ini dikarenakan menurut Sedulur Sikep sesuatu yang bukan miliknya maka ia tidak akan mengambilnya meski itu sampai berhari-hari di sana. Jika ia mengambil barang tersebut sama saja mereka mencuri, walaupun barang tersebut tidak mereka dapatkan dengan mencuri. Tetapi menurut Sedulur Sikep itu adalah perbuatan mencuri karena mengambil barang yang bukan milik mereka.

Selain itu masyarakat Sedulur Sikep ini juga memiliki sebuah pantangan yaitu dilarang untuk berjualan kulak (kulakan) dan dilarang menjadi calo. Karena menurut mereka dengan melakukan hal tersebut maka mereka termasuk orang yang dapat merugikan orang lain. Itu merupakan bukan salah satu prinsip yang diajarkan oleh para orang tua mereka. Selain itu mereka juga menjunjung tinggi adanya kepedulian terhadap lingkungan. Sebisa mungkin hidup mereka digunakan untuk mengabdi kepada ibu pertiwi. Menjaga dan melestarikan alam yang ada di sekitarnya. Banyak dari masyarakat Sedulur Sikep yang ikut turun aksi ketika 
Pegunungan Kendeng, Sukolilo akan dijadikan pabrik semen. Mereka ikut berpartisipasi dalam menjaga bumi pertiwi mereka. Salah satunya ibu Gunarti. Beliau ikut mempertahankan bumi pertiwinya dengan mengadakan aksi di Jakarta. Ikut dalam perundingan dengan Presiden agar tidak mengijinkan pabrik semen dibangun di daerah mereka. Mereka kekeh menjaga agar bumi pertiwi mereka tetap terjaga dan dapat dinikmati oleh anak dan cucu mereka nanti.

Masyarakat Sedulur Sikep juga tidak diperbolehkan untuk menempuh pendidikan formal. Anak-anak Sedulur Sikep dalam belajar membaca, menulis dan menghitung biasanya diajarkan oleh orang tua mereka sendiri. Karena menurut mereka pendidikan utama adalah dari keluarga. Tidak hanya pendidikan budi pekerti tetapi juga pendidikan umum.

Masyarakat Sedulur Sikep ini mempunyai ciri khas dalam menggunakan pakaian. Sedulur Sikep selalu menggunakan pakaian serba hitam dengan ikat kepala untuk laki-laki dan memakai kebaya hitam untuk perempuan. Meski sekarang hal tersebut sudah jarang dilakukan oleh masyarakat Sedulur Sikep tapi hal tersebut masih dipertahankan hingga sekarang.Yaitu digunakan ketika mereka mengadakan sebuah acara khusus atau pun ketika mereka melakukan perkumpulan sesama Sedulur Sikep. Kebudayaan ini masih diajarkan kepada anak-anaknya agar tetap memakai pakaian tersebut ketika menghadiri acara tertentu. Hal ini diungkapkan oleh ibu Nur (40) salah satu tetangga yang berada sekitar masyarakat Sedulur Sikep. Ia kerap kali melihat para masyarakat Sedulur Sikep menggunakan pakaian serba hitam disaat ada acara budaya di Balai Omah Kendeng dan juga ketika menghadiri acara pernikahan sesama Sedulur Sikep. Beliau juga mengungkapkan bahwa di daerah Sukolilo masih banyak kelompok masyarakat Sedulur Sikep. Jadi ketika ada salah satu masyarakat Sedulur Sikep Menikah pasti banyak yang memakai pakaian serba hitam.

Menurut ibu Gunarti (49) mengapa hal tersebut masih dipertahankan hingga sekarang. Karena itu merupakan amanah dari para orang tua dulu. Selain itu pakaian yang mereka gunakan merupakan salah satu identitas mereka sebagai Sedulur Sikep. Prinsip yang mereka pegang hingga saat ini disimbolkan dari cara berpakaiannya mereka. Yaitu menggunakan ikat kepala untuk mengikat tali persaudaraan antar masyarakat Sedulur Sikep. Atau biasanya disebut udeng yang artinya mudeng/paham yaitu paham dengan apa yang ia lakukan dalam kehidupan sehari-hari.

Tujuan menggunakan pakaian tersebut tak lain adalah untuk menghargai sesama Sedulur Sikep, menjunjung tinggi persaudaraan diantara mereka. Karena Sedulur Sikep tersebar di beberapa daerah di jawa. Dengan tetap melestarikan cara berpakaian, menjadi bukti 
bahwa Sedulur Sikep masih memegang nilai-nilai luhur yang telah diturunkan dari para pendahulunya dan tidak tergerus oleh zaman. Dan juga pakaian tersebut mempunyai simbolsimbol yang penuh dengan makna. Hal ini sesuai dengan peribahasa jawa yang berbunyi Ajining Raga Ana Ing Busana. Yang berarti harga diri atau kehormatan seseorang dilihat dari cara berpakaiannya. Suatu contoh, orang yang berpakaian lusuh, kumal, kotor dan compang camping pasti kurang mendapat penghargaan bahkan orang lain segan untuk mendekatinya. Sebaliknya orang yang berpakain rapi, bersih, dan sopan,tentunya lebih disegani dan dihargai. Begitu juga dengan Sedulur Sikep, pakaian yang mereka kenakan adalah sebagai identitas yang melekat pada diri mereka.

Cara berpakaian Sedulur Sikep ini adalah sebagai wujud identitas sosial mereka. Seperti yang diungkapkan oleh Tajfel (1982) Identitas Sosial sebagai bagian konsep diri individuindividu yang berasal dari pengetahuan mereka terhadap keanggotaannya dalam suatu kelompok sosial berdasarkan keterikatan nilai-nilai dan emosi. Teori ini selaras dengan apa yang dikatakan oleh beberapa informan di atas. Cara berpakaian yang khas dari Sedulur Sikep merupakan karakteristik tersendiri yang membedakannya dengan kelompok lain. Cara berpakaian mereka juga mencerminkan bagaimana mereka berhubungan antar sesama makhluk ciptaan Tuhan dan melalui cara berpakaiannya juga, mereka mampu menempatkan diri mereka pada perannya masing-masing dan mengamalkan ajaran yang telah diwariskan dari pendahulunya.

\section{SIMPULAN}

Filosofi dari cara berpakaian masyarakat Sedulur Sikep yaitu menggunakan udeng atau ikat kepala merupakan bentuk simbol mudeng atau paham akan apa yang mereka lakukan dan sebagai bentuk mengikat tali persaudaraan antar masyarakat Sedulur Sikep. Sedangkan tujuan dari masyarakat Sedulur Sikep tetap mempertahankan cara berpakaian khas mereka yaitu untuk menghargai sesama Sedulur Sikep. Selain itu menjadi bukti bahwa Sedulur Sikep masih memegang nilai-nilai luhur yang telah diturunkan dari para pendahulunya dan tidak tergerus oleh zaman. Meski kini mereka menggunakan pakaian khas tersebut ketika ada acara khusus. Sedangkan untuk sehari-hari mereka tetap menggunakan pakaian pada umumnya. Akan tetapi cara berpakaian yang khas dari Sedulur Sikep ini merupakan karakteristik tersendiri yang membedakannya dengan kelompok lain. Hal ini dibenarkan oleh Mbah Sriyono (80) sebagai salah satu tokoh penting di kelompok Sedulur Sikep. Pakaian Khas yang digunakan merupakan 
sebagai simbol bagaimana mereka bersikap dan berpikir serta bagaimana mereka berhubungan antar sesama makhluk ciptaan Tuhan

\section{DAFTAR PUSTAKA}

Eriyanti, F. (2006). Dinamika posisi identitas etnis Tionghoa dalam tinjauan teori identitas sosial. Jurnal Demokrasi, 5(1), 23-34.

Kristanto, V. H. (2018). Metodologi Penelitian Pedoman Penulisan Karya Tulis Ilmiah:(KTI). Deepublish.

Lisdiantini, N., Subiyantoro, S., \& Afandi, Y. (2019). Peranan fashion dan pakaian sebagai komunikasi identitas sosial. Epicheirisi: Jurnal Manajemen, Administrasi, Pemasaran dan Kesekretariatan, 3(1), 9-15.

Munadi, M. (2014). Budaya politik masyarakat Samin (Sedulur Sikep)(studi kasus di Dukuh Bombong Desa Baturejo Kecamatan Sukolilo Kabupaten Pati Provinsi Jawa Tengah). POLITIKA: Jurnal Ilmu Politik, 4(1), 69-79.

Nazir, M.(2005). Metode Penelitian.. Penerbit Ghalia Indonesia.

Setyaningrum, D., Astuti, T. M. P., \& Alimi, M. Y. (2017). Pergeseran nilai masyarakat samin (Sedulur Sikep) dukuh Bombong. Journal of Educational Social Studies, 6(1), 29-36.

Tajfel, H. (1982). Social Identity and Intergroup Relations. Cambridge University Press.

Utami, V. A., \& Irhandayaningsih, A. (2016). Preservasi pengetahuan bagi keberlangsungan indigenous knowledge Masyarakat Suku Samin Kabupaten Pati. Jurnal Ilmu Perpustakaan, 5(1), 101-110.

Widiyanto,Paulus.(1983). Samin Surosentiko dan Konteksnya. Majalah Prisma, No.8, Agustus Tahun XII.

Widyatwati, K. (2017). Pengaruh masuknya budaya populer terhadap eksistensi ajaran sedulur sikep pada Masyarakat Samin. Nusa: Jurnal Ilmu Bahasa dan Sastra, 12(1), 137-146.

Yusuf, A. M. (2014). Metode Penelitian Kuantitatif, Kualitatif, \& Penelitian Gabungan. KENCANA. 